\title{
Ouarsenis/Anc(h)orarius mons ( ?) : note complémentaire sur le nom latin
}

Jehan Desanges

\section{OpenEdition}

1 Journals

Édition électronique

URL : https://journals.openedition.org/encyclopedieberbere/2854

DOI : $10.4000 /$ encyclopedieberbere.2854

ISSN : 2262-7197

Éditeur

Peeters Publishers

\section{Édition imprimée}

Date de publication : 2 juin 2013

Pagination : 5945-5946

ISBN : 978-2-7584-0194-0

ISSN : 1015-7344

Référence électronique

Jehan Desanges, "Ouarsenis/Anc(h)orarius mons ( ?) : note complémentaire sur le nom latin », Encyclopédie berbère [En ligne], 36 | 2013, document 040, mis en ligne le 12 mars 2021, consulté le 17 février 2022. URL : http://journals.openedition.org/encyclopedieberbere/2854 ; DOI : https://doi.org/ 10.4000/encyclopedieberbere.2854

Ce document a été généré automatiquement le 17 février 2022.

(c) Tous droits réservés 


\title{
Ouarsenis/Anc(h)orarius mons ( ?) : note complémentaire sur le nom latin
}

\author{
Jehan Desanges
}

1 L'Anchorarius mons est mentionné par Pline l'Ancien (XIII, 95) en Maurétanie « citérieure », c'est-à-dire césarienne. Il produisait le « citre » le plus estimé, mais cette production est déjà épuisée, comme le précise Pline qui écrit sous Vespasien. Il s'agirait du «Thuya articulé ». Grâce au contexte d'une mention effectuée par Ammien Marcellin (XXIX, 5, 25: Ancorarius mons) au IV siècle de notre ère, il est possible de localiser très approximativement cette montagne : elle n'est pas éloignée de castellum Tingitanum (Chlef, ex-El Asnam, ex-Orléansville) d'où venait l'armée de Théodose qui la traversa pour attaquer la tribu des Mazices*, mal localisée. On tient en général que l'Ancorarius mons correspond au moins en partie à l'Ouarsenis, au sud de la vallée du Chélif, mais St. Gsell (p. 36) en doutait et Ph. Leveau (p. 299-300) y voit des montagnes situées au nord du Chélif, entre la longitude de Ténès à l'ouest et celle d'Aïn-Defla (exDuperré) au sud-est. Mettant en rapport le précoce épuisement de la forêt de thuyas de l'Anc(h)orarius et la relative lenteur de la pénétration romaine, il fait l'observation suivante :

\footnotetext{
"Même en dissociant conquête militaire et commerce, il paraît peu probable que, bien avant la fondation d'Oppidum Novum et le contrôle des régions chélifiennes intervenu dans la seconde moitié du I ${ }^{\text {er }}$ siècle, les thuyas de l'Ouarsenis occidental aient pu être soumis à une exploitation dévastatrice ».
}

Remarquons toutefois que la déforestation a dû plutôt être conduite par les rois de Maurétanie Juba II et son fils Ptolémée ( 25 avant - 39/40 après J.-C.), grands amateurs de tables de citre (Pline, XIII, 92-93) et qui avaient, en principe, autorité sur la Gétulie.

Quoi qu'il en soit, l'oronyme Anc(h)orarius, tel qu'il nous est parvenu, n'a linguistiquement rien de commun avec « Ouarsenis », ni même avec la forme médiévale Wanšariš. On ne peut exclure que les Romains l'aient forgé par déformation d'un nom libyque (ou pré-libyque!), mais, tel quel, il admet une étymologie latine. C'est un adjectif attesté chez César (C. II, 9, 4) et signifiant « qui a rapport à une ancre » ou « aux 
ancres». Rappelons que le nom de l'ancre en latin, emprunté précocement au grec (⿳亠㐅⿲犭火 $\nu \rho \alpha$ ), se présente tantôt sous la forme ancora, plus proche du grec, tantôt sous la forme anchora, un flottement dans l'orthographe que l'on retrouve précisément dans le nom du mont. Pour expliquer le choix de cet adjectif par les Romains en fonction d'oronyme, on en est réduit à proposer des hypothèses fragiles: le profil d'une montagne a pu évoquer celui d'une ancre ou encore le bois de ses arbres a pu être utilisé dans la confection d'ancres. En tout cas, et ceci renforce la thèse de Ph. Leveau, il serait assez naturel que l'adjectif $A n c(h)$ orarius ait été appliqué par des marins à une montagne relativement proche de la mer, à condition toutefois qu'elle ait porté des thuyas jusqu'au début du Principat !

\section{BIBLIOGRAPHIE}

GSELL St., « Observations géographiques sur la révolte de Firmus », Recueil des notices et mémoires de la Société archéologique de Constantine, 36, 1903.

LEVEAU Ph., « Recherches historiques sur une région montagneuse de Maurétanie césarienne : des Tigava Castra à la mer », MEFRA, 89, 1977/1.

INDEX

Mots-clés : Algérie, Antiquité, Onomastique 